\title{
Orientation management in organization as a tool to increase the employee productivity
}

\author{
Ali Hawas Alharbi Marketing Trainer at Technical Collage in Hafar Al-Batin collage (TVTC) \\ Fahad Hawas Alharbi Marketing Trainer at Technical Collage in Hafar Al-Batin collage(TVTC) \\ Khalifah Salman Almadhi Marketing Trainer at Technical Collage in hafer albattin collage (TVTC) \\ Ahmad Naif Alharbi Marketing Trainer at Technical Collage in hafer albattin collage (TVTC) \\ Riyadh Ismaeil Albader Marketing Trainer at Technical Collage in hafer albattin collage (TVTC) \\ ALmalki Mohammad Musallam Marketing Trainer at Technical Collage in hafer albattin collage (TVTC) \\ ALmayouf Abdulmajeed khalled Marketing Trainer at Technical Collage in hafer albattin collage (TVTC)
}

\begin{abstract}
Orientation programs are prudent for the employees in a new environment for undergo plan and strategic orientation to speed up their acceptance into the organization's system. Organizations with policies and guidelines on orientation program remain more relevant and competitive in their business fields because they equip the employees with relevant knowledge, competence, and skills necessary for the modern work place. This study is one of the most important management skills that a human resource manager must possess to give the employees the opportunity to understand the environment where they intend to work. This paper will seek to find answers to three research questions: (i) what is the importance of orientation management to the employee and organization? (ii) What the best ways of managing orientation in an organization?, and (iii) Who is responsible for managing the orientation program in an organization? Research studies involve the process of relevant collective data that would help the researcher to arrive at the right conclusion about the findings. Many research studies have linked the success of the organization to the organization's ability to organize successful orientation programs for the employees. Thus, orientation remains one of the most effective methods of improving productivity in organizations.
\end{abstract}

Keywords: Orientation Program, Productivity, Competence, Strategic orientation, Socialization Process

DOI: $10.7176 / \mathrm{JMCR} / 62-06$

Publication date: November 30th 2019

\section{Introduction}

Orientation programs are critically important for the new employees in an organization. The process of orientation aims at assimilating the new employees to the organization as part of the socialization process. The primary objectives of conducting orientation include gaining the employee commitment, reduce the anxiety, help the new employees to understand the organizational culture, and understand the employee's expectation from the position they intend to hold. It is prudent for the employees in a new environment for undergo plan and strategic orientation to speed up their acceptance into the organization's system (Cummings, G., \& Worley, C., 2014). In addition, the orientation and training is necessary to refresh the knowledge and skills of the employees in an organization. Organizations with policies and guidelines on orientation program remain more relevant and competitive in their business fields because they equip the employees with relevant knowledge, competence, and skills necessary for the modern work place (Cummings, G., \& Worley, C., 2014). This calls for the knowledge and skills of orientation management to ensure that the organization effectively uses that opportunity to illustrate the expectation of the organization of him.

\section{Background information}

Orientation management has been cited as the most effective way to help the employees to acclimatize into the new system and to boost their levels of self-esteem and morale to work. While some professional experts believe that the quality of raw materials, ergonomics, of the work environment, and the quality of equipment determine the production, many other experts believe that the human resource is the most critical determiner of the quality of work output. Human resources are prudent and make the production possible. Ichiniowski, Shaw and Prennushi, (2014), postulate that human resources are key to the success and the achievement of the organizational goals. At such, it means that the human resources must be prepared well to face the challenges of meeting the goals of the organization.

It is important to boost the ability of the employees to meet the laid down goals and objectives of the organization, through proper orientation programs tailored to train them on the expectations of the organization. It saves time for the organization because it jumpstarts the employees by showing the employees the level at which the organization has reached, the achievements and failures and the expected areas that he is needed to work on more than other. The management of such process is critical in the success of the whole process (Cummings, G., \& Worley, C., 2014). First, the managers must ensure that the employee is comfortable with 
venue and time of the orientation. It is highly recommended that the management of the program organizes for the most effective resource persons that would give the employees the information from all perspectives that they can understand.

\section{Rationale of the Study}

Orientation management forms a critical part of an organization that is focused on delivering on its mandates to meet the organizational goals and compete favorably with its competitors. Proper Orientation management prepares the new employees to face the new challenges in the new environment and fast tracks their ability to adapt. For the purpose of creating a working team, the management must ensure that the employees match to the working standards of the old employees to boost production. Orientation management also works towards preventing possible employee bully by the old employees, thus boosting the morale of the incoming workers. Given the diverse business environment in the modern business world, this study will help the human resource managers and organizations facing the challenges of productivity on the formulation of employee training and orientation policy (Cummings, G., \&Worley, C., 2014). Therefore, this study is one of the most important management skills that a human resource manager must possess to give the employees the opportunity to understand the environment where they intend to work. This paper will seek to find answers to the following research questions;

i) What is the importance of orientation management to the employee and organization?

ii) What the best ways of managing orientation in an organization?

iii) Who is responsible for managing the orientation program in an organization?

\section{Literature Review}

Reports from different professionals in management and economists believe that when well-orientated and trained professional employees are fully utilized, they are more likely to benefit the organization. It opens up the opportunity for the organization to develop and survive in the global competitive business world. It is against this backdrop that organizations need to come up with programs and systems that aim at bringing out the essential attention, creativity, and innovation for the individual employees and team members within the organization, especially the incoming members. Orientation is not only important for new employees, but also for the purpose of introducing new programs, systems, cultures, new structures, and the most effective and modern methods of managing their duties and responsibilities. The rapid changes in the business environment require frequent and constant training on the methods to cope with the stiff competition in the global business environment.

According to the study by Buono, (2008), innovative changes are more effective when the employees acquire the new skills, perspectives, skills, and knowledge about them. The study asserts that the introduction of new techniques and systems in the organization requires the employees to get fully involved in implementing the techniques and systems. Therefore, they must be acquainted with the necessary skills and knowledge required to implement the system and the techniques at work. Basically, the knowledge, skills, and perspectives would be taught and trained during the orientation training and programs. The training would boost the morale, motivation, the competence, and the attitude of the employees.

There are various factors that influence the growth and development of organization in the modern business era. Employee training and orientation plays a critical role in enhancing the performance of the employees to increase the productivity level. Increased productivity is key to elevating the organizations above the rest in the global market because of improved competitive advantage of the organization. There is a marked difference between organizations that organize regular training and orientations for its employees, both new and old and the organizations that rely on the employees personal innovations.

Various research studies have linked performance of the employees to orientation and training. Ichniowski, Shaw, and Prennushi, (2014) examined the performance of the employees before and after orientation and training. Ichniowski, Shaw, and Prennushi, (2014) found out that the work output of employees that have undergone orientation programs is relatively higher than the employees that have not been trained. On the same note, Hollings (2007) contended that employee's proficiencies undergo significant transformation after training by boosting their competency, knowledge, attitude, and remarkable personality development of the employees.

Personal development is key to the achievement of both individual and organizational goals. It is important that employees continuously improve in their areas of expertise and acquire new skills that can help them at personal level. According to Cummings, T. and Worley, C., (2014), orientation is critical in promoting personal growth of the employees at work, both the new employees and the existing. While the organization may be focused in equipping the employees with the skills for the work performance, the knowledge is prudent for the employees' personal development. Personal development is key to the improvement of productivity at work. A study conducted by Trkman, P. (2013) opined that organizations should encourage employees' personal 
development because it is vital for the organization's success. Personal development improves a person's intellectual ability, personality, emotional intelligence and other aspects of the employee that determine their effectiveness at work. Employees with good personality are great assets to the organization because they maintain good public relations, maintain teamwork, and can easily take initiatives that are geared towards meeting the goals of the organization.

A study by Delaney and Huselid, (2013) found out that human resource training, development activities, and orientation aim at equipping the workers with the necessary competence for the successful performance in their various duties and responsibilities within the organization. This study postulates that the failure to equip the employees with the required skills and competence is assure way to render the organizations failed because they may not cope with the changing business environment in the global business world (Delaney and Huselid, 2013). The study also points out that lack of proper orientation leaves the employees poorly motivated, and lacking the skills and competence in the given field. Competence is one of the most important requirements for an employee in any organization that needs success (Delaney and Huselid, 2013).

According to a study conducted by Earley (2007) found out that employees require the competence to perform their duties and responsibilities in the given organization. This is required in various levels of the organization such as the managerial, technical, and personality competencies. The study further suggests that orientation is important in equipping the employees with the necessary managerial, technical, and personality competencies. On the same note, Earley (2007) also found out that the current employees, especially the young employees find training and orientation opportunities as beneficial to them in terms of equipping them with the knowledge and skills they need to carry out their duties. The study survey also found out that most of the employees prefer working in organizations that organize frequent and continuous training and orientations (Earley, 2007). In this regard, it is imperative that organizations have the opportunity for the supervisors, managers, and the employees to identify, define, and assess their competitiveness of the skills to carry out their duties and responsibilities.

Training and orientation have numerous benefits for the organization and the individual employees. For the organization, they are able to impact their organizational cultures, and structure on the employees. This way, the organization will be able to effectively implement their policies using the new and old employees. According to (Hollings, 2007), training is the process of impacting knowledge to the employees to equip them for the performance of their duties. The author also believes that training at work is a form of job orientation. The study also notes that training is accorded to the employees to increases efficiency, improvement, and safety of the machines used at the organization. On the same note, Ichniowski, Shaw, and Prennushi, (2014) stated that training improves the competence of the employees, which transforms their attitude towards their tasks at the organization. According to the study, training boosts the morale and motivates the employees, thus reducing the gap between the performance of the workers and the achievement of the goals of the organization.

Ichniowski, Shaw, and Prennushi, (2014) also postulated that the orientation and training is also important because it creates both external and internal competitiveness among the workers. Orientation and training in areas such as the use of modern technology provides the employees with the zeal to take up their responsibilities seriously and enhance competition. According to the study, competition is enhanced through training of the employees because the employees seize the opportunity to show their ability to learn the new skills in technology and apply them effectively in their areas of specialization (Ichniowski, Shaw, and Prennushi, 2014). Internal competition in an organization is critical for the purpose of improving the quality of work (Hollings, 2007). This is because each employee will use the knowledge and skills they acquire to show their fellow colleagues that they are better than them. Consequently, there will be both improvement in the quality of the work output and the production.

Employee orientation and training have been cited as the primary as being the key to capacity building of the organization. In addition, it is essential for the development of efficient and service delivery (Ichniowski, Shaw, and Prennushi, 2014). It is prudent in enhancing the understanding of newly hired employees to enable them master specific skills that are relevant to the specific organization that has hired them.

\section{Methods of data collection}

Research studies involve the process of relevant collective data that would help the researcher to arrive at the right conclusion about the findings. The method of data collection depends on the research question and the focus of the research (Taylor, S. J., Bogdan, R., \& DeVault, M. 2015). In most cases, the researcher determines the type of method to use based on the study hypothesis of the study. Principally, there are two major methods of collecting data for a research study. These methods include quantitative and qualitative research methods (Merriam, S. B. 1998). Quantitative research methods include the use of data that includes figure and texts from interviews, questionnaires and surveys.

On the other hand the qualitative research method relies information from texts and other research studies that have been conducted by other researchers (Merriam, S. B. 1998). For the purpose of this study, I will 
use a qualitative content analysis method to collect data. Qualitative content analysis is the use of literatures that other people had written about the same and related topic (Merriam, S. B. 1998). The paper will seek to validate some of the assertions of the researchers based on the relevance and the depth of the information.

\section{Data Analysis Methods}

Data analysis is important for scholarly research studies because it helps in coming up of the right findings for the study. The rights methods of data analysis depend on the type and nature of the data that the researcher collected (Taylor, S. J., Bogdan, R., \& DeVault, M. 2015). For instance, data that involves the use of statistics and figures would require the analyst to apply regression analysis to come up with a proper conclusion and findings of the study. The researchers must ensure that they choose the right method to analyze the given data, using the right tools that conform to the type of data that they have collected (Taylor, S. J., Bogdan, R., \& DeVault, M. 2015). Before a research study can be validated as being relevant and correct, the data collected must be collected and analyzed using scientifically accepted methods of data analysis methods. Like the methods, there are qualitative and quantitative data analysis methods that one can use to analysis data. Quantitative data analysis includes the use of figures and texts to analyze the data collected. In most cases, the quantitative data analysis method is applied to data that require the analysis of figures. This method is more accurate in terms of arriving at the right figures that reflect the findings of the study.

Quantitative data analysis is prudent for the purpose of conducing analysis such as regression analysis. Scientific studies make use of the quantitative data analysis because it is accurate and gives the researcher an opportunity to conduct abroad research analysis (Bryman, A., \& Bell, E. 2015). On the other hand, the qualitative data analysis is the evaluation of the resources used in the study to ensure that they are valid and contain the relevant information about the topic of study. The qualitative data analysis is based on the grounded theory practices, mostly answering the question "why?" qualitative data analysis is applied in questionnaires, interviews, and focus groups (Taylor, S. J., Bogdan, R., \& DeVault, M. 2015). It is also critical for the data collected through observation. The major advantages of this method of data analysis because it focuses not only on the figures of the data but facts that are primarily collected through interviews, questionnaires, and observation. The method is also effective because it uses the inductive methods of data analysis to develop theories from the data that have been gathered. For the purpose of this study, I intend to use qualitative data analysis method to analyze the data from the field.

There are various methods can organizations can apply in enhancing the process of orientation and creating a culture of employee training and orientation. With proper structures, organizations can create an enabling environment whereby the employees get the opportunity to train and gain new and relevant knowledge about their areas (Ichniowski, Shaw, and Prennushi, 2014). These strategies include setting aside special budget and human resource for the facilitation of the process, thus making it part of the organization's culture. It is of great importance to note that the human resource is key to the success of the organization in terms of productivity (Ichniowski, Shaw, and Prennushi, 2014). Therefore, investing in the training and orientation of the employees is imperative. On the same note, organizations should focus on formulating policies that guide the selection and orientation programs for the new employees that join the group (Trkman, P., 2013).

The organizations should formulate policies that focus on the improvement the employees" personal growth. According to Cummings, G., and Worley, C., (2014), the improvement and development of personal growth is critical for the growth of the organization and for the future of the organization. An employee that has undergone the personal growth and development is more focused on meeting the goals of the organization and learning more from the training.

\section{Conclusion}

The significance of orientation management in an organization cannot be over-estimated. Employees need to undergo refresher orientations that are tailored towards the growth of the organization and increasing the quality and quantity of production (Buono, A., 2008). Orientation increases productivity by equipping the employees with the current and relevant skills and knowledge that are critical for productivity of the organization. In addition, when introducing new company policies and structures. Making company changes is can only be successful if the human resource management makes the necessary arrangement to train the existing employees about the new policies and practices (Trkman, P., 2013). In this regard, the employees will have an opportunity to learn the new skills and competency in performing certain tasks that would help in increasing the productivity (Buono, A., 2008). Productivity is one of the most important target The human resource manager must plan for proper orientation programs for the new employees to help them reduce the anxiety, get along with the serving employees, state their expectations and also to introduce them to the culture of the organization. Many research studies have linked the success of the organization to the organization's ability to organize successful orientation programs for the employees. Therefore, orientation remains one of the most effective methods of improving productivity in organizations. 


\section{References}

Delaney, T., \& t., Huselid, A., (2013). The impacts of human resource management practices in the perceptions of organizational performance. Academy of management journal 39(4), 949-969.

Merriam, S. B. (1998). Qualitative research and case study applications in education. Revised and expanded from. Jossey-Bass Publishers, 350 Sansome St, San Francisco, CA 94104.

Buono, A. (2008). Management Human Resources: Productivity, quality of work Life, Profits. Personnel Psychology 51(4), 1041.

Trkman, P. (2013). Increasing process orientation with business process management: Critical practices'. International Journal of Information Management, 33(1), 48-60.

Bryman, A., \& Bell, E. (2015). Business research methods. Oxford University Press, USA.

Ichniowski, C., Shaw K., \& Prennushi, G., (2014). The effects of human resource management practices on productivity: A study of Steel finishing lines. The American Economic Review, 291-313.

Wright C., \& Geroy, D., (2009). Changing the Mindset: the training myth and the need for the world class performance. International Journal of Human Resource Management 12(4) 586-600.

Taylor, S. J., Bogdan, R., \& DeVault, M. (2015). Introduction to qualitative research methods: A guidebook and resource. John Wiley \& Sons.

Cummings, T. G., \& Worley, C. G. (2014). Organization development and change. Cengage learning. 